\title{
Engaging Children to Co-create Outdoor Play Activities for Place-making
}

\author{
Geertje Slingerland \\ Delft University of Technology \\ Delft, The Netherlands \\ g.slingerland@tudelft.nl
}

\author{
Stephan Lukosch \\ HIT Lab NZ, University of Canterbury \\ Christchurch, New Zealand \\ stephan.lukosch@canterbury.ac.nz
}

\author{
Frances Brazier \\ Delft University of Technology \\ Delft, The Netherlands \\ f.m.brazier@tudelft.nl
}

\begin{abstract}
Outdoor play activities are one of the ways via which children can acquire a sense of place towards their neighbourhood. Engaging children in the design of these activities through Participatory Design (PD) holds promise. However, knowledge lacks on the characteristics of place-making processes for children, the changing dynamics in these processes, and how PD can contribute to this. This paper proposes a PD method, grounded in literature, to support children in co-creating outdoor play activities for place-making. The method is applied with 42 children in Rotterdam. Involvement of local partners, preparation meetings, and PD materials tailored to children's interests and skills are vital to enable children to design outdoor play activities that are meaningful to them.
\end{abstract}

\section{CCS CONCEPTS}

\section{- Human-centered computing $\rightarrow$ Participatory design.}

\section{KEYWORDS}

Place-making, Outdoor play, Children, Participatory design, Neighbourhood engagement

\section{ACM Reference Format:}

Geertje Slingerland, Stephan Lukosch, and Frances Brazier. 2020. Engaging Children to Co-create Outdoor Play Activities for Place-making. In Proceedings of the 16th Participatory Design Conference 2020 - Participation(s) Otherwise - Vol 1 (PDC '20: Vol. 1), June 15-20, 2020, Manizales, Colombia. ACM, New York, NY, USA, 11 pages. https://doi.org/10.1145/3385010.3385017

\section{INTRODUCTION}

Future transitions and societal challenges in today's cities mandate citizen participation and engagement. In fact, citizens need to take responsibility for their neighbourhood and collaborate on taking action to improve it $[12,34]$. Engagement between citizens in their local community [2,3,13], knowing what is happening [17], and interaction between neighbours $[1,21]$ is vital to the sense of belonging [33]. This holds not only for adults but also for children.

Various interaction design interventions have been studied to stimulate citizen participation and engagement, but they mainly focus on adult users. Although children are the future of the city, know very well what they need to enjoy life in the city, and have

Permission to make digital or hard copies of part or all of this work for personal or classroom use is granted without fee provided that copies are not made or distributed for profit or commercial advantage and that copies bear this notice and the full citation on the first page. Copyrights for third-party components of this work must be honored For all other uses, contact the owner/author(s).

PDC '20: Vol. 1, June 15-20, 2020, Manizales, Colombia

(c) 2020 Copyright held by the owner/author(s).

ACM ISBN 978-1-4503-7700-3/20/06.

https://doi.org/10.1145/3385010.3385017 the right to express these needs [14], they are not always included in the development of the urban space [9, 36, 41]. Involving children in decision-making encourages them to take ownership of their environment [36], become more active and engaged in their neighbourhood [26], with increasing trust towards municipal actors $[35,40]$, enabling them to feel more at home in their local community [38]. It is thus important for children to connect with their direct living environment, to acquire a sense of belonging [31, 48] and civic agency [37].

One of the ways via which children can acquire a connection with the neighbourhood is by building a relationship with the physical environment [31]. Some papers (e.g. [9, 31, 36]) call this process place-making [36]. Place-making can facilitate children's connection with the physical space of their neighbourhood and hence provide the pathway for children to become engaged and feel a sense of belonging towards their local environment. Nonetheless, more research into place-making is necessary, as current placemaking processes are, by some, considered to be uninspiring and irrelevant for children [36], and the dynamics of involving children in such processes are not properly understood [9].

In the literature, Participatory Design (PD) has shown to be a promising approach to engage children in design processes not related to place-making $[8,9,16,20]$. This paper investigates whether PD with children can be used to this purpose. This paper builds on the limited amount of promising research (e.g. [10, 29, 36, 48]) with the same goal to explore which PD methods and activities are most appropriate when working with children. Researchers indeed claim that PD methods can increase sense of place, but it is not clear how this exactly happens and which elements of the PD process contribute to this.

To sum up, more understanding is needed on the characteristics of relevant place-making processes for children [36], how dynamics change when children are involved in these processes [9], and how PD methods contribute to increase a sense of place [20]. This paper addresses these three knowledge gaps by studying a PD process designed to support children in the design of their own place-making activities. The study explicitly considers the dynamics between the involved adults and children, and includes a detailed discussion and reflection on the PD activities and materials used. The presented outcome and contribution of this paper are the considerations and challenges of using PD to facilitate meaningful place-making for children. These insights contribute to the three identified research gaps and can be used in designing future PD projects to engage children in place-making activities. 


\section{BACKGROUND}

This section discusses the state of the art for the three research gaps addressed in this paper: 1) designing relevant place-making processes, 2) changing dynamics when involving children in PD for place-making, and 3) using PD to increase a sense of place. Each section ends with a paragraph to describe the insights from the literature on which the PD method proposed in this paper are based. The specifics of this method are further described in Section 3.

\subsection{Place-making processes for children}

The first identified research gap is about relevant place-making processes for children. Outdoor play is proposed as a meaningful place-making activity for children [31, 32, 48]. Physical exercise benefits children's development [31,32], and also supports children's relationships with their neighbourhood [31, 43]. Outdoor play enables children to explore their environment and make active use of it [20, 31], to construct meaning and identity [9], and to enable children to take ownership of their environment [48]. It is supported most in open-ended play: a type of play in which there are no fixed rules and children keep on (re)inventing games and play behaviour [6]. Outdoor play can happen anywhere and take many shapes and forms $[6,48]$. The current literature shows two ways of facilitating such outdoor play for place-making: through changing landscape environment $[5,32,48]$ and through enhancing the environment with interactive technology $[4,6]$.

Research on landscape environments discusses how the physical environment can support outdoor play. Physical elements can provide features for outdoor play for place-making [48]. For example, a sequence of stepping stones could encourage children to move in unexplored areas [5]. Interestingly, children and adults have very different ideas about what could be a good environment for outdoor play [20]. Francis [20] showed that playgrounds designed by children are more engaging, compared to ones designed by adults. Back et al. [6] had similar findings, noting that when children were unsupervised by parents new types of interaction with play installations emerged, leading to new forms of meaningful interaction. While the public playground serves as a natural place for outdoor play [32], a varied landscape allows more flexibility in terms of social roles amongst children and thus a more interesting play experience [5].

Another way to facilitate outdoor play is by augmenting the physical environment with interactive technology $[4,6]$. This is especially relevant in urban spaces, where natural environments, considered ideal for outdoor play [20,31], are less accessible for children [20]. Many studies have been conducted to design and evaluate interactive interventions to facilitate children's outdoor play (e.g. [31, 32, 48]), exploring the design space of outdoor play technology [45]. These interventions can support children to explore their surroundings [43]. Examples of interventions to support outdoor play include tangible play objects, augmented playgrounds, and wearable devices [32]. Children invent their own games around such simple interactive technology [22], and these outdoor play activities support social interaction and engagement with places in the neighbourhood [32, 48].

Outdoor play is proposed as a meaningful way of engaging children in place-making processes. To design for such experiences, understanding the local context, i.e. the physical and societal aspects, is vital, especially to ensure relevance of place-making for children [6]. In this process, children need to have flexibility [42] to define their own rules [22], and social interaction and collaboration are key [32, 42].

To conclude, prior research suggests that place-making can become relevant for children when considering the physical environment as well as using interactive technology to enhance the space [44]. A method to invite children to consider outdoor play activities that can be played using the physical elements of their neighbourhood, potentially complemented with a digital mobile app, would seem in line with these findings. Further, as social interaction and collaboration are identified as key elements to successful placemaking [32, 42], they should be central in both the PD method and activities. Finally, the need for flexibility for children to create their own rules of game for meaningful interaction is well-recognised $[22,42]$. Children as co-researchers [47] is an approach with which they can design their own place-making activities, and should be included in the PD approach designed.

\subsection{Dynamics in PD with children}

Involving end-users in design to create systems that they need and like is not new [28]. In PD, future users are actively and directly engaged in the design process [39]. While children were long excluded from this process, they are now acknowledged as competent design partners [16, 23], having credible voices to which to be listened $[8,14,25]$. Technologies take a more prominent role in children's lives $[15,25]$ and adults have a very different perspective on these compared to children [23]. While much work has been done, it remains a challenge to truly involve children in design as equal partners [16, 24]. This is partially due to the second knowledge gap addressed in this research, namely not properly understanding the difference in the dynamics when children are involved.

One of these differences is related to the impact that PD processes have on their participants [25]. In long term engagements, children and designers can build strong relationships [7, 15]. Children discover that they have the ability to make a change $[14,25]$ and feel empowered $[11,47]$ because they can express their values and identity [11]. These values are then considered and valued by adult designers [16, 23, 24], and enable children to create designs that increase their quality of life [23]. Further, children can learn valuable skills throughout the PD process [25, 47], such as working with other people [16], communication skills, and design knowledge [11,25]. These outcomes of mutual learning [7] are named design-centred learning by Druin [15]. Finally, PD activities have also reported to change children's attitudes positively, by increasing confidence [11], competence [24], and creating a sense of ownership and legitimacy [24, 25].

Another dynamic is related to the adults whom participate in the PD processes, for example teachers, care-givers, or parents [7]. Original PD concerns include democracy, power, politics, and ability to act [24] and these aspects need to be considered for PD with children as well [25]. Designers need to question to what extent their $\mathrm{PD}$ process enables children to affect decisions concerning their life [24] and creates equal power relationships between children and designers [7]. While adults might negatively influence the PD 
process, they can also act as proxies to increase children's interest [7]. The more children are familiar with the topic of the PD process [7], know what is expected of them [16], and the characteristics of a good design [39], the better they can participate.

Therefore, the main insights with regard to changing dynamics is that time is needed for all involved participants to learn to work together within a given context $[6,24,43]$, to understand expectations [7, 16, 24, 39], and for children to feel responsible for their actions knowing their opinion is valued [47]. Druin [15] proposes practical ways to decrease the power distance, namely by dressing informally, using informal language, and explicitly asking children for their opinion. Iversen et al. [25] proposes that researches should be introduced as design experts instead of teachers. The importance of preparation and time to get to know one another in advance are important factors for the design of successful interventions.

\subsection{PD tools for place-making}

PD methods are used to enable children to have their voice heard in shaping their city [20] and to connect to places in the neighbourhood that are meaningful to them [48]. Scholars have started to acknowledge that children have valuable insights in the places they use and have the capacity to re-invent these places [9]. Simultaneously, children are excited when being asked about their community life; they feel valued for their culture and ideas [14] However, which elements of PD increase children's sense of place is not well understood, limiting their application in future endeavours.

In doing PD with children, the methods need to be adjusted $[15,16]$ to fit children's levels $[8,23]$ and to create a common language between adult and child designers [18]. Prototypes could, for example, enable a shared understanding [24]. Druin [15] proposes cooperative inquiry as an approach for PD with children. In her research, children become equal partners in the design process [16], requiring long-term engagement. As such resources are not always available [16], Hussain [23] suggests that also with simple PD techniques, children should be able to effectively communicate their needs [11].

Prior research that applied PD for place-making uses mapping [10], neighbourhood walks [6, 36], location-based games [29], and multiplayer participatory simulations [27] that allowed children to address concerns about their neighbourhood. While some of these studies have a slightly different focus than place-making (e.g. addressing local concerns [36], or creating a game for a civic issue [29]), they all address topics related to place-making and provide some valuable insights on how children can co-design interventions in their environment. As local experts, children are well equipped to take researchers on a walk in the city or to map the neighbourhood on paper [10], presenting the city, its issues and opportunities, to the research team [36].

Accordingly, the activities included in current literature are all focused on encouraging children to act as local experts and show the researchers what would be meaningful place-making activities for them. The literature shows that children can be empowered to be the local experts, to design their own meaningful place-making activities in neighbourhood walks [20,36, 48]. The use of journals as a means for children to develop their own thoughts and ideas proposed by Druin [16], Hussain [23], and Wood et al. [48], shows to be a valuable support for creativity. Furthermore, others $[8,15$, $16,23]$ demonstrate the importance of providing age-appropriate materials and having a variety of ways for children to participate, based on their own preferences. Children should be able to choose the role they prefer to fulfil - focusing on taking pictures, talking, drawing, writing, or a mixture of those for them to communicate their needs and wishes during the PD work in a way they prefer $[11,16,23]$.

\section{METHOD}

A PD process with children was designed and implemented on the basis of the insights reported above to address the three research gaps identified in this research. This PD process was tried and tested with primary school children in Rotterdam (NL). The children are the local experts of their neighbourhood. They were asked to design place-making activities that are meaningful to them. Table 1 provides an overview of the activities that were all part of the applied method. The next paragraphs outline the specifics of the method, including the research context, the procedure, the data, and the analysis.

\subsection{Research context}

The research was performed in Tarwewijk, a neighbourhood in Rotterdam, with a very diverse population of about 12,000 citizens. This area is located in the southern part of Rotterdam, historically infamous for crime rates, drug abuse, and poverty [46]. Recent investments from the municipality made very significant improvements, but Tarwewijk is still considered a 'problem area'. A neighbourhood with challenges has a dynamic flow of citizens moving in and out of the neighbourhood and a significantly lower average yearly income per household compared to the rest of the country (€16,500 compared to $€ 23,000)$. Tarwewijk, however, is a neighbourhood of the future: $25 \%$ of its inhabitants are aged below 25 years. Policies of the municipality to increase liveability and safety of this area are thus mainly focused on children as is the presented research.

3.1.1 Involved local partners. The research was set up and executed in collaboration with several local partners: VeldAcademie, Cultureel Denkwerk, and primary school CBS De Akker. VeldAcademie is a research and consultancy bureau specialised in collecting citizen input using field research, for example to inform urban planning processes for the municipality of Rotterdam. This bureau worked with children from Tarwewijk of the same age group before and has pedagogical knowledge to inform the designers involved in this project on appropriateness of the materials and tasks. The second local partner is Cultureel Denkwerk, a culture and arts think tank that has worked for many years in this neighbourhood. Their recent interest is to explore how technology, such as digital games, can be used to increase children and youngsters' chances in life. This institution connected the research team to CBS De Akker, the primary school where the research was performed. This school has a long tradition of engaging in (research) projects that involve improving the lives of their children. The school's interest is to increase children's sense of place and to stimulate exploration, enabling these children to broaden their perspective and increase their chances in life. 
Table 1: The proposed method consists of five activities, all based on insights from prior research.

\begin{tabular}{|c|c|c|c|}
\hline Timing & Activity & Local partner & Aim \\
\hline Nov 2018 & $\begin{array}{l}\text { Neighbourhood walk by professional } \\
\text { stakeholders }\end{array}$ & $\begin{array}{l}\text { Cultureel Denkwerk, } \\
\text { two researchers }\end{array}$ & $\begin{array}{l}\text { Understand social and physical context } \\
\text { of neighbourhood [6] }\end{array}$ \\
\hline Nov 2018 & $\begin{array}{l}\text { Meeting with school director to discuss } \\
\text { expectations and workshop setup }\end{array}$ & $\begin{array}{l}\text { Cultureel Denkwerk, } \\
\text { CBS de Akker, two } \\
\text { researchers }\end{array}$ & $\begin{array}{l}\text { Align local partners and manage expec- } \\
\text { tations [7] }\end{array}$ \\
\hline Nov 2018 & $\begin{array}{l}\text { Meeting with VeldAcademie to discuss } \\
\text { workshop materials and activities }\end{array}$ & $\begin{array}{l}\text { Cultureel Denkwerk, } \\
\text { VeldAcademie, two } \\
\text { researchers }\end{array}$ & $\begin{array}{l}\text { Collect toolkit of relevant and appropri- } \\
\text { ate materials and activities for children } \\
{[15,16,23]}\end{array}$ \\
\hline Dec 2018 & $\begin{array}{l}\text { First school visit to introduce research } \\
\text { team, explain workshop setup and hand } \\
\text { out booklets }\end{array}$ & $\begin{array}{l}\text { Cultureel Denkwerk, } \\
\text { CBS de Akker, two } \\
\text { researchers }\end{array}$ & $\begin{array}{l}\text { Getting to know each other and build- } \\
\text { ing trust. Know what researchers expect } \\
\text { of children and what children expect of } \\
\text { researchers }[7,16,24,39]\end{array}$ \\
\hline Dec 2018 & $\begin{array}{l}\text { PD workshop in which children form } \\
\text { groups, choose a role, and walk through } \\
\text { the neighbourhood to design outdoor } \\
\text { play activities }\end{array}$ & $\begin{array}{l}\text { Cultureel Denkwerk, } \\
\text { CBS de Akker, five } \\
\text { researchers }\end{array}$ & $\begin{array}{l}\text { Children co-create outdoor play activ- } \\
\text { ities for place-making on their terms } \\
{[14,22,32,36,42]}\end{array}$ \\
\hline
\end{tabular}

3.1.2 Research participants. In consultation with the school director, the choice was made to design for the 7th grade children (aged ten to twelve years) as they are old enough to have some sense of their neighbourhood, come up with ideas, and have the potential to be followed up with in their final school year. Almost all of these children live close to the school. The school has two 7 th grade classes with 42 children in total. These groups both participated in the research as explained further below.

3.1.3 Informed consent. All local partners provided informed consent for participation in this research project and to be included in this paper. Special attention was given to acquiring the consent of the children. Informed consent was ensured through the parents. The school translated informed consent forms into the native language of parents (when needed), distributed them, and ensured they were returned.

\subsection{Procedure}

Table 1 provides an overview of all research activities that were undertaken to prepare and execute the PD method.

3.2.1 Preparations. Several meetings were organised with the local partners to align and manage their expectations and to acquaint the research team with the neighbourhood and the school. During the kick-off meeting with the school director, Cultureel Denkwerk, and the research team, the overall purpose of the workshop was set and collaboration between partners was discussed: the PD workshop on which this paper reports was a pilot for future research endeavours. The school, as well as the other partners, were interested in the design and development of a digital mobile application that will encourage children to go out and explore their neighbourhood. The work presented in this paper was considered to be the first step, for the partners to get acquainted, but also to see how the research team works with the children and how the children respond to the research team. If the results of the first PD workshop were successful and meaningful to the children, the next step would be to implement the designed outdoor play activities in a mobile app and play these with the children in a second workshop, to understand how these could increase children's sense of place.

The third preparation meeting was with the VeldAcademie and focused mainly on discussing the initial design of the workshop setup and materials. Due to the VeldAcademie's earlier experience of working with similar children, the materials and activities were also based on their insights. For example, they proposed to provide children with a booklet before the workshop to help them prepare, and to assign each child a specific task to keep them engaged during the workshop.

3.2.2 Materials. Different materials were prepared to support the PD method as summarised in Table 2. One week prior to the actual workshop, children received two documents. The first was a piece of paper depicting examples of outdoor play activities that they could design. These designs were photo-shopped on a mobile phone screen, already showing the children how their designs might become part of an actual mobile app. The second document was a booklet, personalised with the name and photo (received from the school) of each child, with questions for the children to answer, to start reflecting on the potential for outdoor play in their neighbourhood. The booklet also served the purpose of getting acquainted: the main facilitator introduced herself with some general information (age, current residence, hobbies, and favourites, like outdoor play game or colour), and children were asked to do the same. On the following pages of the booklet, the children were asked to draw a picture of their home, indicate its location on a map and write what they (dis)like about their street. Next, they were asked to explain which kind of activities they usually do out on the streets and which outdoor games they play and with whom. Finally, children were asked to write what they are proud of (considering their neighbourhood), indicate on a map which places they (dis)like in Tarwewijk, and explain why. An example of two of these questions in the booklet is shown in Figure 1. The other materials were used one week later, during the PD workshop, and mainly 
Figure 1: Two questions from the booklet, asking the child to 1) tell what they like to do outside, and 2) indicate places they like and dislike in their neighbourhood.

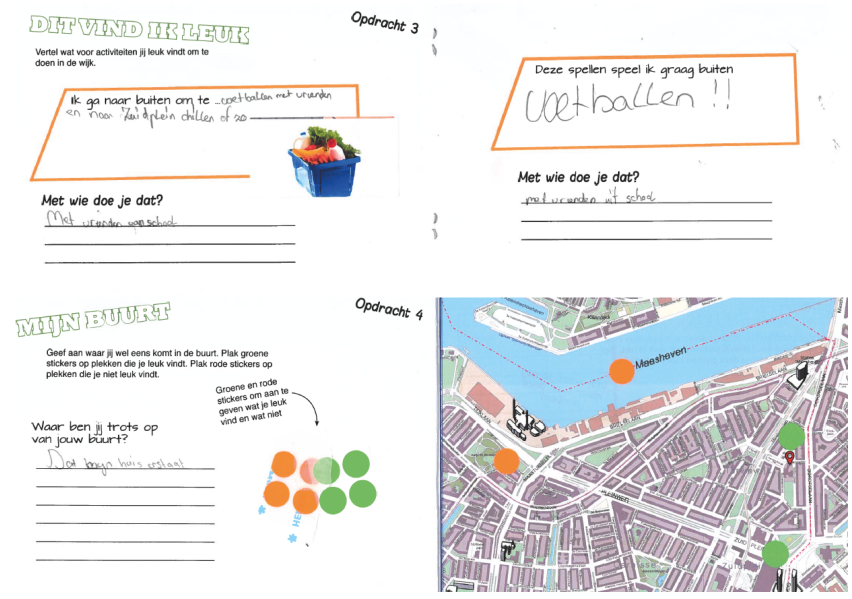

served to support children in executing their chosen role (navigator, photographer, reporter, note-taker, or drawer), and to document the group process. Most materials are published in the supplementary materials of this paper or can be requested from the first author.

3.2.3 First school visit. One week prior to the workshop, two researchers and a representative of Cultureel Denkwerk visited the school for both the adults and children to get to know each other. The introduction took about 20 minutes and was already quite interactive: children asked different types of questions to the researchers (where they lived, what they do) and the researchers encouraged children to share their experiences with the researchers and fellow classmates (e.g. what games they play outside). Further, the workshop setup was explained and the booklets and A4 sheets of paper with example activities were handed out. The researchers explicitly told the children that they might come back a few months later with a mobile application that the children could test, based on the ideas they would generate in the coming workshop.

3.2.4 Workshop. The following week, the workshop was held in two rounds and took about 60 minutes per round. Knowing the children individually and as a group, their teacher determined the composition of the groups each with three to five children (in line with a recommendation by [39]). In total, nine groups of children participated in the PD workshop. Each group was assigned a researcher and another adult guardian (arranged by the school). Before going outside, children chose the role they wished to take. The main purpose of the roles was to make sure each child had a task during the workshop, but in principle one child could also fulfil multiple roles at the same time. Five different roles were available from which children could choose:

- Navigator: child reads the route descriptions and guides the group on the walk

- Photographer: child is given a camera and is asked to take pictures of interesting places and the group process
Table 2: Table presents the materials that were developed for the project, their purpose and the activity for which they were used.

\begin{tabular}{|c|c|c|}
\hline Material & Purpose & Activity \\
\hline Booklets & $\begin{array}{l}\text { Engage children to already start } \\
\text { thinking about their neighbour- } \\
\text { hood, the things they like to do } \\
\text { outside, and the outdoor activi- } \\
\text { ties they would like to design }\end{array}$ & $\begin{array}{l}\text { First school } \\
\text { visit }\end{array}$ \\
\hline $\begin{array}{l}\text { Activity ex- } \\
\text { amples }\end{array}$ & $\begin{array}{l}\text { Prompt children with possible } \\
\text { ideas for outdoor play activities }\end{array}$ & $\begin{array}{l}\text { First school } \\
\text { visit }\end{array}$ \\
\hline $\begin{array}{l}\text { Location } \\
\text { cards }\end{array}$ & $\begin{array}{l}\text { Manual for the whole group } \\
\text { with a short description of a lo- } \\
\text { cation to start the brainstorm } \\
\text { for a play activity }\end{array}$ & Workshop \\
\hline Role cards & $\begin{array}{l}\text { Describe each of the roles and } \\
\text { what the child needs to do in } \\
\text { that role }\end{array}$ & Workshop \\
\hline $\begin{array}{l}\text { Route de- } \\
\text { scriptions }\end{array}$ & $\begin{array}{l}\text { Manual for navigating child to } \\
\text { find the route }\end{array}$ & Workshop \\
\hline $\begin{array}{l}\text { Mobile } \\
\text { phone }\end{array}$ & $\begin{array}{l}\text { Probe for reporting child to doc- } \\
\text { ument the group process }\end{array}$ & Workshop \\
\hline Camera & $\begin{array}{l}\text { Probe for photographing child } \\
\text { to take pictures of interesting } \\
\text { places or what happens in the } \\
\text { group }\end{array}$ & Workshop \\
\hline $\begin{array}{l}\text { Location } \\
\text { maps }\end{array}$ & $\begin{array}{l}\text { Probe for drawing child to draw } \\
\text { outdoor play ideas on }\end{array}$ & Workshop \\
\hline $\begin{array}{l}\text { Activity } \\
\text { forms }\end{array}$ & $\begin{array}{l}\text { Probe for the writing child to } \\
\text { note down the created outdoor } \\
\text { play activities }\end{array}$ & Workshop \\
\hline
\end{tabular}

- Reporter: child is given a mobile phone with a recording application and is asked to interview the group members and report on what is happening

- Note-taker: child is given a clipboard and a pencil, and is asked to write down the ideas that the group comes up with on the activity forms

- Drawer: child is also given a clipboard, pencils and a paper, and asked to make a drawing of the outdoor play activity on the provided location maps

Following suggestions from prior research (e.g. [14, 36, 48]), children and researchers walked through the neighbourhood to understand children's experiences in the outdoor space and enable children to ground their ideas in the context. Each group walked one of three different routes (three different groups were assigned to each route) and stopped at specific locations to brainstorm about ideas. Each brainstorm was prompted by a location card, but children could also choose other locations on route for outdoor play activities. Although the group was accompanied by adults, the children were in the lead and adults acted as observers and only facilitated the group process when needed. This meant that the children were in charge of the co-creation process and decided which locations and outdoor play activities were meaningful to 
Figure 2: One of the groups discussing outdoor play activities.

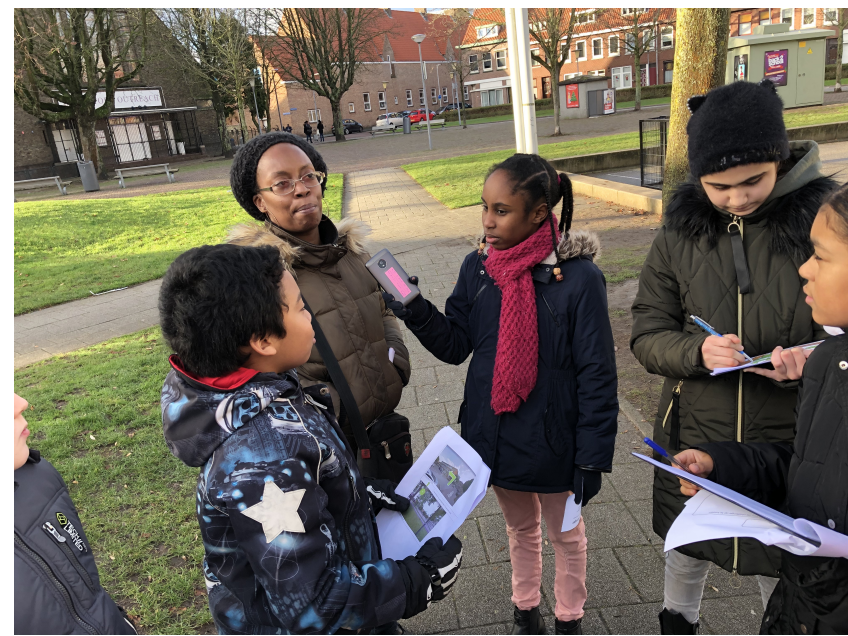

them. Figure 2 shows one of the groups discussing outdoor play activities. Each route had a distance of about one kilometre and covered different areas in Tarwewijk. Children had on average approximately ten minutes per location to brainstorm about ideas.

3.2.5 Data collection. Data was collected from the researchers whom accompanied and observed the groups during the workshop, written on observation sheets with which they were provided in advance. An observation sheet allows for a fairly uniform way of collecting data across researchers in different groups [6]. The researchers were asked to focus on how the children worked together to create activities, and other interesting things children mentioned in relation to the neighbourhood [32].

Further, data was collected from the booklets, the transcripts from the reporter recordings, the pictures taken by the photographers, and the writings and drawings produced by the note-takers and drawers. Sources using multiple methods provides a rich basis for analysis [16].

3.2.6 Data analysis. All data (forms, transcripts, and booklets) were coded by three independent researchers. Following from the research question, five initial categories were used to start the inductive open coding process [49] :

- Process supporting co-creation: codes to describe how and which parts of the method supported children to co-create outdoor play activities

- Meaningful outcome: codes to indicate whether the process was meaningful to the children

- Current activities in the neighbourhood: codes to describe activities in the neighbourhood in which children currently participate

- Like to do: codes to describe what children like to do in their neighbourhood

- Current perception of the neighbourhood: codes to describe how children currently perceive their neighbourhood
After the first round of coding, the research team discussed the codes and patterns found in the data using axial coding. Each researcher started the axial coding for one of the categories, and later switched to another category to check the axial coding of another researcher. When the grounds for classification were unclear or interpretation of the codes differed between researchers the team sought and found consensus, thus deepening understanding of the specific meanings of the codes. One week later, the team met again and went through all the coded patterns in another round of coding to further interpret the patterns, to finalise and document the analysis.

\section{RESULTS}

The results are presented in relation to the three research gaps distinguished in the introduction: 1) what are relevant place-making processes for children, 2) how do dynamics change when involving children in these processes, and 3) what elements of PD methods support place-making. The first section presents how the children responded to the PD method and materials, which is related to gaps 1 and 2. The second section discusses the outdoor play activities children designed and considered to be meaningful, contributing to gap 1 and 3 . The final section describes the opportunities these outdoor play activities provide for children to have meaningful place-making with their neighbourhood, providing insights for gap 3.

\subsection{PD process and materials}

The results indicate that, in general, children enjoyed the PD activities and materials. For example, one child wrote in her booklet " $I$ really liked the assignment and I hope to learn a lot more about my neighbourhood". Another child said at the end of the PD workshop: "Today was really nice. Unfortunately, we can only do this once". Another one said: "Is it over already?" when the group was walking back to school. Children were actively trying to come up with the first idea for an outdoor play activity. While some children seemed to be genuinely interested to think about outdoor play activities, others seemed to just enjoy being outside and were less engaged in the brainstorming. One observer for instance noted about a group: "This group is not very enthusiastic about designing activities, they mainly like to run around". Although one observer wrote that he needed to help the group come up with ideas at some locations, most observers reported that children independently came up with ideas during the PD workshop. In sum, the PD materials and activities facilitated idea generation of outdoor play activities and were enjoyed by the children. Next, a reflection is given on the role of the different tasks, booklets, physical environment, and where the process and materials matched and mismatched children's skills and interests.

4.1.1 Reflection on roles and tasks. The children decided themselves which roles they wished to play up front. Group negotiation was sometimes necessary when multiple children wanted to take the same role. These roles sometimes changed during the course of the workshop. The role of the photographer, for example, was very popular. The children passed the camera along when requested. When, in one group, the observer asked one child why he liked 
Figure 3: Children enjoyed to ask neighbours for their input while generating ideas for outdoor play activities.

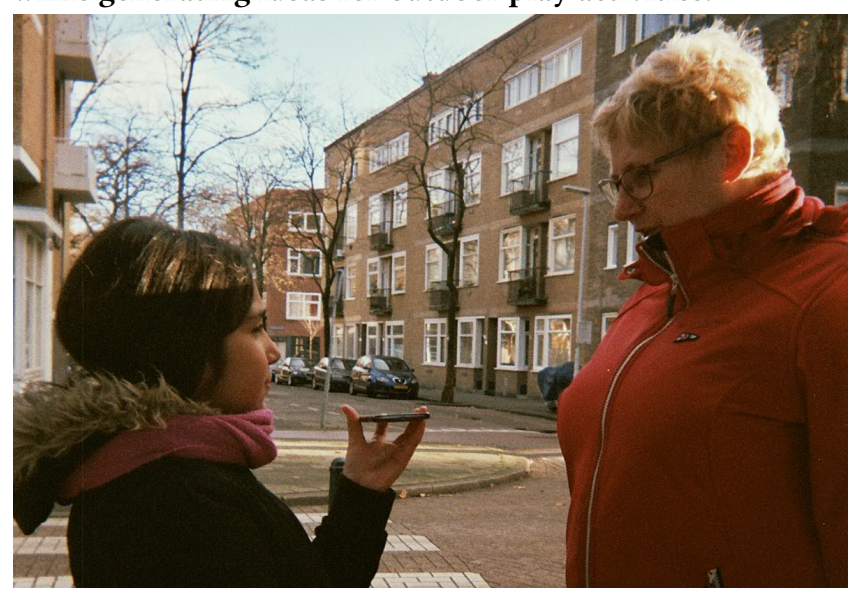

taking pictures so much, the reply was "It just feels so good to push that button".

Children were free to choose how to come up with ideas for outdoor play activities. The location cards were a prompt to start the brainstorm, asking children to consider the environment, but otherwise they were free to explore other locations and other ideas. One of the things the children particularly liked was to make contact with people on the streets. One child said: "I want to go to people and ask them questions". Another group suggested to have an outdoor play activity that was about "Asking people questions, just asking questions". The observer asked what the questions would be about and the group replied: "Ask questions about what you think about the neighbourhood". Children spontaneously started to interview citizens in Tarwewijk about what they thought about the location and how it might be improved (see Figure 3).

The roles helped to keep children engaged in the co-design of play activities. Some children were very immersed in their role, like one child who took her role as a reporter very seriously and acted as if she was a radio reporter narrating everything that happened within the group. Children also checked with each other whether they were doing the tasks that were part of their role, for example asking the photographer: "Did you already take a picture of that?" This led to the whole group taking responsibility for keeping each group member engaged in the design process.

4.1.2 Booklets. The booklets were handed out to 42 children and 32 were returned. Of these 32 , eleven had been filled out completely (all five pages), 14 filled out three pages or more and six booklets were filled out only one or two pages. Some children really enjoyed to filling out the booklets, while others wrote that the booklet "was difficult to fill out". The booklets were not further discussed with the children, but mainly served for researchers and children to get familiar, build trust, and prompt the children to start thinking about their neighbourhood. This limited the amount of information that could be gathered from the booklets, because some children wrote down things that would need extra explanation to be properly interpreted. For example, many children wrote down which games they like to play outside but did not elaborate on why they liked these particular games. This could have become clear when discussing the booklet with a child. However, this was not possible within the time the school allocated for the PD workshop.

4.1.3 Role of the physical environment. The children walked around the neighbourhood to come up with ideas for outdoor play. What they saw around them, was input for their ideas. Physical objects or locations they passed by were associated with previous experiences, for example one child saying "We used to go to this building for the physical education classes", when walking past this particular building. The physical environment around the children triggered them to come up with ideas or initiated certain thoughts that were shared. On one occasion, children walked past a large iron box, of which they did not know what it was. They started to discuss what it could be, taking a closer look, and finally opening the box to see what was inside. One child exclaimed "Wooww, take a picture of that!!" when the box was opened and the whole group was very excited with their discovery. In fact, the box showed them what was under the ground: a piping infrastructure providing the water to the nearby houses.

Children further started to introduce their neighbourhood to the observers and to each other. For example, one child asked another "Do you come here often?", and the other replying: "Not really, I used to come here. I don't know... I started to find the place a bit scary". Or one child who presented the local shopping mall Zuidplein to the observers and said "Some people call Zuiderpark Zuidje", another one child added: "But for us, Zuidplein is Zuidje". The children thus showed the observers the locations in the neighbourhood to which they feel connected and that are meaningful to them.

4.1.4 Mismatches. Although most PD materials and activities supported children to design outdoor play activities, some did not match children's abilities or interests. During the workshop, one child asked another if they had an idea and she replied "No, I just want to go home". In total, six occasions were noted by observers or in the transcripts of the recordings of children not enjoying themselves. Furthermore, not all children understood their role, the corresponding tasks, and that these roles all contributed to the design process. One child asked the observer "Why do we need to make games out of everything?", showing that this particular child did not understand the purpose of the PD workshop, despite our efforts to explain this to the children up front. Three children further asked questions such as "Miss, should I write this down?", or "What should I take pictures from?", indicating they did not feel free to execute their task in a way they saw fit. As the workshop took place during school time, it might be that children thought they would be assessed on their performance in the workshop, especially because there were adults walking with the groups, observing them and writing down what the group was doing.

Mismatches also occurred because tasks such as writing and drawing required skills or knowledge that a couple of children lacked. Some children were struggling to come up with outdoor play ideas. One child, who was the reporter, asked another one what they think about the workshop and he replied "I don't know, I find it a bit difficult". One child specifically mentioned that she was 
shy and therefore had problems participating. An observer noted that "Child has difficulty to write it down", an another one wrote "The drawer doesn't know what to draw. Children discuss this". Finally, one location card asked children to consider the history of their neighbourhood to come with an outdoor play activity. Children were unfamiliar with this aspect of their neighbourhood, limiting their ability to come up with ideas on this location.

\subsection{Meaningful outcome}

Children designed several outdoor play activities and showed the researchers what is meaningful to them. These design outcomes, as well as what children learnt about the neighbourhood, is reported in the next section.

4.2.1 Design outcome: outdoor play activities. The groups came up with 50 ideas in total for nine different locations. The ideas enabled varied ways of playing outside and, according to Back et al. [5], thus lead to a meaningful play experience. Children thought about physical play activities to make locations more interesting, such as running next to the metro to see if you can be faster than it. The mobile application would then be used to track the time and keep an overview of the high-scores. They also came up with quiz challenges for which children need to find the answer to a question about the location, for example what the meaning of a local statue is or what the factory at the other side of the street is producing. To find the answer, children needed to talk to people around or find street signs that provide the information and fill out the answer in the app to see if it is correct. Finally, the groups came up with ideas that required other children to add new things to the neighbourhood. For instance, designing a playground on a currently boring square. These creations could then be uploaded to the app and be evaluated by other children to choose the winner.

For one group, the observer noted that children felt proud of the outdoor play activities they had designed. In another group, the reporter asked the other children how the neighbourhood could be improved. One child replied: "Well, that all those dogs, here close to the playgrounds and the park, all dogs just poop here."

Reporter child: "So that you would like to change?"

Child: "Yes"

Reporter child: "And then the neighbourhood would become even nicer?"

Child: "Yes, a cleaner neighbourhood."

These children apparently felt ownership towards the neighbourhood and that they have an ability to make a change.

4.2.2 Learning about the neighbourhood. While children walked through the neighbourhood, they started to ask questions about physical objects, buildings, and locations they passed by. For example: "What do these statues there mean? Why are they there?" or "What do these flags refer to?". These questions would sometimes become a play activity, finding the answer to this question by inspecting the environment or talking to people around who might know the answer.

Children started to tell stories to each other about the neighbourhood during the walks. For example, one child started to tell about a building: "It has been there since 2003, but before it was... I read it on the website of De Akker, this place used to be apartments."
Children also learnt new things about neighbourhood locations. In the recording transcripts, children explicitly showed that they had learnt something, like one child exclaiming: "Oh!!! Because there are all these wheat factories located here!', when he started to understand why their neighbourhood is called Tarwewijk (tarwe is wheat in Dutch). In other cases it followed from children asking questions or reflecting on something they saw. Therefore, by walking through the neighbourhood, children were supported to learn from others and broaden their perspective.

\subsection{Fostering place-making}

The aim of creating outdoor play activities using a PD approach was to increase children's sense of place. The booklets especially gave a lot of insight into how children perceive their neighbourhood and how they connect to it.

In the booklets, children mentioned that they want to have a pleasant neighbourhood and this is determined by the physical space as well as the neighbours who are out on the streets. Children said that they want adults to take them seriously and consider them as part of the neighbourhood. Children were explicitly asked in the booklets what they were proud of in their neighbourhood. Five children said they did not like their neighbourhood and were not proud of it. Others (13 children) mentioned some places that they are proud of, such as the shopping mall Zuidplein. Two children said they think everything is great about their neighbourhood.

Almost all children mentioned in their booklets that they like their neighbourhood because they can play. They want to play with children of their own age. They like to go outside, to one of the playgrounds, and play together with their friends. Children mentioned several locations, like shops, playgrounds, or particular streets, that they like and dislike in their neighbourhood. Three children reported that they liked their neighbourhood or street because they live there. They feel it is their home. Outdoor play and the close environment around the child's home are thus two very important elements for facilitating meaningful place-making for children.

\section{DISCUSSION}

The next section reflects on what the results of the study contribute to the three knowledge gaps identified at the beginning of the paper.

\subsection{Meaningful place-making}

The first research gap is related to place-making processes currently not being relevant for children. This paper has presented a PD approach to support children in the design of outdoor play activities for place-making that are meaningful to them. Lentini and Decortis [31] present six factors that can be used to evaluate whether an activity supports place-making and our results show that these factors were present in the applied PD approach. The location cards prompted children to physically explore their neighbourhood (factor 1) by walking through it, but also for example asking them to look around and find interesting objects, or to use a parkour as a basis for an outdoor play activity. On one occasion, children found a large box and started to examine it, as described before (factor 2). The results further show that children started to share their local knowledge about the neighbourhood, for instance 
telling each other about a landmark that they know or a square where they always play a certain game. The PD approach seems to have encouraged children to exercise their spatial skills (factor 3) and develop their knowledge on how places in the neighbourhood are used (factor 4). Children are considered the experts of their neighbourhood and are given the responsibility to show to the researchers which outdoor play activities are meaningful to them. Children came up with valuable outdoor play designs, showing that they feel responsible and valued (factor 5). Finally, the activities and materials had individual elements (such as the booklets), but the main part is the PD workshop in which children had to collaborate to come up with ideas, eliciting face-to-face interactions and collective experiences (factor 6).

The taken approach thus contains the factors of Lentini and Decortis [31] to facilitate a sense of place, and indicate other elements that need to be taken into account to evaluate such effect. As reported by others [24, 44, 47], it is not always easy to gather insights on why children did certain things, because children have difficulty to remember and reflect on their own experiences. This impacts how much understanding researchers can acquire on what is meaningful place-making for children, especially when the time spent with children is limited. In case of long term engagements between children and researchers, such as in the work done by Druin [16], deeper insights can be gathered, but this seems to be difficult to realise in projects where the engagement with children is only for a short period of time. For this project specifically, a follow up takes place with the children, in which the researchers and children can further build their relationship, potentially allowing for a better understanding on what place-making activities these children need.

\subsection{Changing dynamics}

Children were engaged as co-researchers [47], as they were asked to go outside and explore opportunities for outdoor play in their neighbourhood. They also influenced the design process as informants [16], by coming up with ideas for outdoor play activities that would be later incorporated in a mobile app that they would again test. The involved adults would, on the contrary, mainly act as facilitators, creating the opportunity for hybrid practices [7] to take place. These occur at moments where the worlds of the researchers and children come together and they participate in each other's activities. The researchers facilitating children to design outdoor play activities (normally a practice of the design researcher) in the children's neighbourhood is an example of such a practice, and according to Barendregt et al. [7], provides a good environment for all actors to participate. This study shows how important it is for the researchers to not interfere in the process of the children, only when they are asked to, allowing children to take the lead and participate in a way that they prefer.

However, the results also indicate the potential influence of executing the design activities within the school environment. In the school context especially, children are used to listen to what adults say [16]. Furthermore, children aged above ten years have notions of the way things are 'supposed to be', limiting their creativity and carefree participation [15]. These aspects might all have played a role in the presented outcomes, as all children were above ten years old and the results report various situations in which children seem to seek confirmation of the researchers or teachers that they were doing well. Such empowerment and especially the notion of power therein is extensively discussed within PD. Authority is a controversial concept [7], but must be considered in the presented research because of the school context [24]. When PD activities are part of the schoolwork, own interest and voluntarily participation are not necessarily underlying the work [24]. The school setting in which the research was undertaken, may have influenced the participation of these children.

Despite the disadvantages, schools are often the best way to acquire access to children [7] and thus executing PD projects with children in a school environment might be inevitable. Therefore, investing time with the local stakeholders, such as the guardians around the children, is a vital part of doing this kind of research but not always reported as such [30]. The preparation meetings and activities undertaken for this research project are thus very important, to get to know each other, build trust, manage expectations, and align goals. This relationship does not only need to be established between local partners, but especially between children and researchers.

\subsection{PD for place-making}

The third research gap this paper addresses is the potential of PD materials and activities to facilitate place-making of children. The materials and activities used in this research are based on cooperative inquiry as proposed by Druin [15], albeit not including prototyping. To ensure age appropriate materials for the children, the preparation meeting with local stakeholders were relevant, as they had the expertise and previous experience of working with these children. In general, the materials and activities supported the children to participate in the design process, as reflected in the huge amount of interesting outdoor play activities the children designed.

Resonating with findings from others (e.g. [23, 45]), behaviour of children in PD processes can be different than expected. It is thus important to design a process that is flexible and allows children to participate on their terms. Depending on their experience [24], PD materials and tasks should be adjusted to the child's needs and skills $[23,37]$, and should allow children to adapt them towards their own preference. The results report several examples of children doing this: using materials in a different way than initially intended or changing roles and tasks throughout the workshop. Not only the materials and tasks, but also the roles provided children with the opportunity to participate according to their preference. How children behaved within a certain role differed significantly between children. Some children wanted to keep their role throughout the process, while others preferred to switch roles. The groups negotiated this amongst themselves, seldom interference of the observer was necessary. This indicates that the materials, tasks, and roles in the PD process provided the children guidance on what they should do, and enough freedom to adapt them to how they saw fit.

\section{CONCLUSION}

Children need to build a relationship with their living environment, to acquire a sense of belonging [31, 48] and civic agency [37]. Prior 
research shows that outdoor play activities can serve as a means for this purpose $[9,36]$ : through outdoor play children explore their environment [20,31], and construct meaning and identity to it [9]. Participatory design (PD) methods with children are proposed as a means to create engaging environments and tools for outdoor play, as children have a very different perspectives on outdoor play compared to adults [20]. However, knowledge lacks on what are relevant place-making activities for children, how the dynamics change when children are involved in these activities, and which elements of PD foster children's connection with their neighbourhood.

This paper has introduced a PD method, based on insights from prior work, and applied this method to engage 42 children in Rotterdam, NL, in co-creation of outdoor play activities. The results show that this method supports interesting and relevant place-making for children. During the PD workshop especially, the method invites children to physically explore their neighbourhood and through designing outdoor play activities with the group, their knowledge on the neighbourhood increases. The applied method creates the dynamics between adults and children in which the children are in the lead and adults acted as facilitators. The preparation meetings are crucial to become acquainted with local stakeholders and the children, to understand their dynamics, and take measures to build trust between all participants, especially when such research takes place within the school context. Finally, the PD materials and activities that are part of the method are suitable for placemaking, but should provide the flexibility for children to adjust them to their preference. Expertise from local stakeholders is again vital to prepare appropriate materials. The results show that a variety of materials should be available for children to decide their level and way of participation. The presented method successfully implements this factor by inviting children to choose a role, having corresponding responsibilities to the co-creation process and documentation of it.

The contribution of this paper is a PD approach with a set of activities that allow children to co-create outdoor play activities for place-making. Children came up with a large variety of ideas for outdoor play, and throughout the process also learned new things about their neighbourhood. The method thus enables children to broaden their perspective and to explore new parts of their neighbourhood. In our most recent research [19], the designed activities are implemented in a mobile application and play tested by the same and a new group of children. These play tests show that children enjoyed playing the activities they themselves had designed and that these activities further strengthened their engagement with the neighbourhood. Hence, engaging children in designing activities for place-making is rewarding, can lead to meaningful outcomes and increase children's engagement with their neighbourhood.

\section{ACKNOWLEDGMENTS}

The authors thank the local institutions (i.e. the VeldAcademie, Cultureel Denkwerk and C.B.S. de Akker) and the children who contributed to and participated in this research. Acknowledgements also go to Xavier Fonseca for all his support, Cindy van der Wijst and Carmel de Nies for their help with the data analysis, and to all other research assistants who helped out during the workshops.

\section{REFERENCES}

[1] W. Neil Adger. 2006. Vulnerability. Global Environmental Change 16, 1 (2006), 268-281. https://doi.org/10.1016/j.gloenvcha.2006.02.006

[2] Richard P Adler, Judy Goggin, and George W Bush. 2005. What Do We Mean By "Civic Engagement"? Journal of Transformative Education 3, 3 (2005), 236-253. https://doi.org/10.1177/1541344605276792

[3] Mariam Asad and Christopher A Le Dantec. 2015. Illegitimate Civic Participation: Supporting Community Activists on the Ground. In Proceedings of the 18th ACM Conference on Computer Supported Cooperative Work \& Social Computing. ACM, 1694-1703.

[4] Jon Back, Caspar Heeffer, Susan Paget, Andreas Rau, Eva-Lotta Sallnäs Pysander, and Annika Waern. 2016. Designing Children's Digital-Physical Play in Natural Outdoors Settings. In Proceedings of the 2016 CHI Conference Extended Abstracts on Human Factors in Computing Systems. 1359-1366. https://doi.org/10.1145/ 2851581.2892416

[5] Jon Back, Caspar Heeffer, Susan Paget, Andreas Rau, Eva-Lotta Sallnäs Pysander, and Annika Waern. 2016. Designing for Children's Outdoor Play. In Proceedings of the 2016 ACM Conference on Designing Interactive Systems (DIS '16). 28-38. https://doi.org/10.1145/2901790.2901875

[6] Jon Back, Laia Turmo Vidal, Annika Waern, Susan Paget, Eva Lotta, and Sallnäs Pysander. 2018. Playing Close to Home: Interaction and Emerging Play in Outdoor Play Installations. In Proceedings of the 2018 CHI Conference on Human Factors in Computing Systems. 1-11. https://doi.org/10.1145/3173574.3173730

[7] Wolmet Barendregt, Peter Börjesson, Eva Eriksson, Olof Torgersson, Tilde Bekker, and Helle Marie Skovbjerg. 2018. Modelling the Roles of Designers and Teaching Staff when Doing Participatory Design with Children in Special Education. In PDC'18: Proceedings of the 15th Participatory Design Conference - Volume 1, Vol. 1. 1-11. https://doi.org/10.1145/3210586.3210589

[8] Mathilde Bekker, Julie Beusmans, David Keyson, and Peter Lloyd. 2003. KidReporter: a user requirements gathering technique for designing with children. Interacting with Computers 15 (2003), 187-202. https://doi.org/10.1016/S09535438(03)00007-9

[9] Jo Birch, Rosie Parnell, Maria Patsarika, and Maša Šorn. 2017. Creativity, play and transgression: children transforming spatial design Creativity, play and transgression: children transforming spatial design. CoDesign 13, 4 (2017), 245260. https://doi.org/10.1080/15710882.2016.1169300

[10] Fabio Campos and Leiny Garcia. 2018. Fostering civic engagement through native maps: a preliminary study. In Interaction Design \& Children. 605-610. https://doi.org/10.1145/3202185.3210780

[11] Merijke Coenraad, Jen Palmer, Diana Franklin, David Weintrop, M Coenraad, J Palmer, D Franklin, and D Weintrop. 2019. Enacting Identities: Participatory Design as a Context for Youth to Reflect, Project, and Apply their Emerging Identities ACM Reference format. In Interaction Design \& Children. 185-196. https://doi.org/10.1145/3311927.3323148

[12] Tina Comes. 2016. Designing for networked community resilience. Procedia Engineering 159 (2016), 6-11. https://doi.org/10.1016/j.proeng.2016.08.057

[13] M. de Lange and M. de Waal. 2013. Owning the city: New media and citizen engagement in urban design. First Monday 18, 11 (2013).

[14] Victoria Derr. 2015. Integrating community engagement and children's voices into design and planning education. CoDesign 11, 2 (2015), 119-133. https: //doi.org/10.1080/15710882.2015.1054842

[15] Allison Druin. 1999. Cooperative Inquiry: Developing New Technologies for Children with Children. In Proceedings of the CHI Conference on Human Factors in Computing Systems. 99-113. http://www.cs.umd.edu/hcil

[16] Allison Druin. 2002. The Role of Children in the Design of New Technology. Behaviour and Information Technology (BIT) 21, 1 (2002), 1-25. http://legacydirs. umiacs.umd.edu/\{ $\}$ allisond/child \{ \} info\{_\}tech/Druin-BIT-Paper2002.pdf

[17] Sheena Lewis Erete. 2015. Engaging Around Neighborhood Issues. In Proceedings of the 18th ACM Conference on Computer Supported Cooperative Work \& Social Computing - CSCW'15. 1590-1601. https://doi.org/10.1145/2675133.2675182 arXiv: $10.1145 / 2675133.2675182$

[18] Eva Eriksson, Gökçe Elif Baykal, Staffan Björk, and Olof Torgersson. 2019. Using Gameplay Design Patterns with Children in the Redesign of a Collaborative Co-located Game. In Interaction Design \& Children. 15-25. https://doi.org/10. $1145 / 3311927.3323155$

[19] Xavier Fonseca, Geertje Slingerland, Stephan Lukosch, and Frances Brazier. Submitted. Designing for meaningful social interaction in digital serious games. (Submitted).

[20] Mark Francis. 1998. Negotiating between children and adult design values in open space prolects. Design Studies 9, 2 (1998), 67-75.

[21] Keith Hampton and Barry Wellman. 2003. Neighboring in Netville: How the Internet Supports Community and Social Capital in a Wired Suburb. City \& Community 2, 4 (2003), 277-311. https://doi.org/10.1046/j.1535-6841.2003.00057.x

[22] Tom Hitron, Andrey Grishko, Idan David, Iddo Wald, Avihay Bar, Eitan Moriano, and Oren Zuckerman. 2017. Scratch Nodes: Coding Outdoor Play Experiences to enhance Social-Physical Interaction. In Interaction Design \& Children. 601-607. https://doi.org/10.1145/3078072.3084331 
[23] Sofia Hussain. 2010. Empowering marginalised children in developing countries through participatory design processes. CoDesign 6, 2 (2010), 99-117. https: //doi.org/10.1080/15710882.2010.499467

[24] Netta Iivari and Marianne Kinnula. 2018. Empowering Children through Design and Making: Towards Protagonist Role Adoption. In PDC'18: Proceedings of the 15th Participatory Design Conference - Volume 1, Vol. 1. Hasselt and Genk, Belgium, 1-10. https://doi.org/10.1145/3210586.3210600

[25] Ole Sejer Iversen, Rachel Charlotte Smith, and Christian Dindler. 2017. Child as Protagonist: Expanding the Role of Children in Participatory Design. In Proceedings of the 2017 Conference on Interaction Design and Children (IDC'17). ACM, New York, 27-37. https://doi.org/10.1145/3078072.3079725

[26] Reinout Kleinhans, Maarten Van Ham, and Jennifer Evans-Cowley. 2015. Using Social Media and Mobile Technologies to Foster Engagement and Self-Organization in Participatory Urban Planning and Neighbourhood Governance. Planning Practice and Research 30, 3 (2015), 237-247. https://doi.org/10.1080/02697459. 2015.1051320

[27] Vishesh Kumar and Mike Tissenbaum. 2019. City Settlers - Participatory Games to Build Sustainable Cities. In Interaction Design \& Children. 660-663. https: //doi.org/10.1145/3311927.3325343

[28] Susanne Lagerström, Iris Soute, Yves Florack, and Panos Markopoulos. 2014 Meta-Designing Interactive Outdoor Games for Children: A Case Study.. In Interaction Design \& Children. 325-328. https://doi.org/10.1145/2593968.2610483

[29] Julie Lamarra, Apoorva Chauhan, and Breanne Litts. 2019. Designing for Impact: Shifting Children's Perspectives of Civic and Social Issues Through Making Mobile Games. In Interaction Design \& Children. 274-279. https://doi.org/10. 1145/3311927.3323338

[30] Christopher A. Le Dantec and Sarah Fox. 2015. Strangers at the Gate: Gaining Access, Building Rapport, and Co-Constructing Community-Based Research. In Proceedings of the 18th ACM Conference on Computer Supported Cooperative Work \& Social Computing. ACM, 1348-1358. https://doi.org/10.1145/2675133.2675147

[31] Laura Lentini and Françoise Decortis. 2010. Space and places: when interacting with and in physical space becomes a meaningful experience. Personal and Ubiquitous Computing 14 (2010), 407-415. https://doi.org/10.1007/s00779-0090267-y

[32] Yudan Ma, Annemiek Veldhuis, Tilde Bekker, Jun Hu, Steven Vos, tuenl Ahmveldhuis, studenttuenl MMBekker, tuenl JHu, and tuenl SVos. 2019. A Review of Design Interventions for Promoting Adolescents' Physical Activity. In Interaction Design \& Children. 161-172. https://doi.org/10.1145/3311927.3323130

[33] David W. McMillan and D M Chavis. 1986. Sense of community: A definition and theory. Special Issue: Psychological sense of community, I: Theory and concepts. Journal of Community Psychology 14, 1 (1986), 6-23. arXiv:0090-4392/96/04031511

[34] Sara Meerow, Joshua P. Newell, and Melissa Stults. 2016. Defining urban resilience: A review. Landscape and Urban Planning 147 (2016), 38-49. https://doi.org/10. 1016/j.landurbplan.2015.11.011

[35] Sarah Nelson and Norma Baldwin. 2002. Comprehensive Neighbourhood Mapping: Developing a Powerful Tool for Child Protection. Child Abuse Review 11, 4 (2002), 214-229. https://doi.org/10.1002/car.741

[36] Sean Peacock, Robert Anderson, and Clara Crivellaro. 2018. Streets for People Engaging Children in Placemaking Through a Socio-technical Process. In Proceedings of the 2018 CHI Conference on Human Factors in Computing Systems. https://doi.org/10.1145/3173574.3173901

[37] Barry Percy-Smith. 2010. Councils, consultations and community: rethinking the spaces for children and young people's participation. Children's Geographies 8, 2 (2010), 107-122. https://doi.org/10.1080/14733281003691368

[38] Jon L. Pierce, Tatiana Kostova, and Kurt T. Dirks. 2001. Toward a Theory of Psychological Ownership in Organizations. The Academy of Management Review 26, 2 (2001), 298-310.

[39] Janet Read, Peggy Gregory, Stuart Macfarlane, Barbara Mcmanus, Peter Gray, and Raj Patel. 2002. An Investigation of Participatory Design with Children-Informant, Balanced and Facilitated Design. In Interaction Design \& Children. Eindhoven, 53-64. https://pdfs.semanticscholar.org/aab3/ ceea74962e7a8b40fc011f423556a0467387.pdf

[40] Francesca Rizzo, Alessandro Deserti, and Onur Cobanli. 2016. Service Design in Public Sector: Boosting innovation through design. In Fifth Service Design and Innovation conference. 448-457.

[41] Jeremy Roche. 1999. Children: Rights, Participation and Citizenship. Child hood 6, 4 (1999), 475-493. https://journals.sagepub.com/doi/pdf/10.1177/ 0907568299006004006

[42] Ankita Samariya, Jerry Alan Fails, and Derek Hansen. 2019. Investigating the Social and Temporal Aspects of Children's Physical Activity Games. In Interaction Design \& Children. ACM, 616-622. https://doi.org/10.1145/3311927.3325312

[43] Susanne Seitinger. 2009. Designing for Spatial Competence. In Interaction Design \& Children. $123-130$. https://doi.org/10.1145/1551788.1551810

[44] Iris Soute, Maurits Kaptein, and Panos Markopoulos. 2009. Evaluating Outdoor Play for Children: Virtual vs. Tangible Game Objects in Pervasive Games. In Interaction Design \& Children. 250-253. https://doi.org/10.1145/1551788.1551844
[45] Iris Soute, Susanne Lagerström, and Panos Markopoulos. 2013. Rapid Prototyping of Outdoor Games for Children in an Iterative Design Process. In Interaction Design \& Children. 74-83. https://doi.org/10.1145/2485760.2485779

[46] Meindert Van der Kaaij. 2018. In de Rotterdamse Tarwewijk groeit de kloof tussen rijk en arm. https://www.trouw.nl/nieuws/in-de-rotterdamse-tarwewijkgroeit-de-kloof-tussen-rijk-en-arm\{ $\} \mathrm{b} 8576 \mathrm{db} 1 \mathrm{~d} /$

[47] Fenne van Doorn, TUDelftnl Mathieu Gielen, and TUDelftnl Pieter Jan Stappers. 2014. Children as Co-Researchers: More than Just a Role-Play. In Proceedings of the 2014 Conference on Interaction Design and Children (IDC'14). 237-240. https://doi.org/10.1145/2593968.2610461

[48] Gavin Wood, Thomas Dylan, Abigail Durrant, Pablo E Torres, Philip Ulrich, Amanda Carr, Mutlu Cukurova, Denise Downey, Phil Mcgrath, Madeline Balaam, Alice Ferguson, John Vines, Shawn Lawson, and Philip I N Ulrich. 2019. Designing for Digital Playing Out. In CHI '19 Proceedings of the 2019 CHI Conference on Human Factors in Computing Systems. 1-15. https://doi.org/10.1145/3290605. 3300909

[49] Robert K. Yin. 2003. Case Study Research: Design and Methods. SAGE Publications, California. 